\title{
Wave and Wind Responses of a Very-Light FOWT with Guy-Wired-Supported Tower: Numerical and Experimental Studies
}

\author{
Hideyuki Suzuki ${ }^{1}$, Hiroki Shiohara ${ }^{1}$, Anja Schnepf ${ }^{2}$, Hidetaka Houtani ${ }^{1}$, Lucas H. S. Carmo ${ }^{3}$, \\ Shinichiro Hirabayashi ${ }^{4}{ }^{\oplus}$, Ken Haneda ${ }^{5}$, Toshiki Chujo ${ }^{5}$, Yasunori Nihei ${ }^{6}$, Edgard B. Malta ${ }^{7}$ \\ and Rodolfo T. Gonçalves 1,* \\ 1 OSPL-Ocean Space Planning Laboratory, Dept. of Systems Innovation, The University of Tokyo, \\ Tokyo 106-0032, Japan; suzukih@sys.t.u-tokyo.ac.jp (H.S.); hiroki.shiohara328@gmail.com (H.S.); \\ houtani@sys.t.u-tokyo.ac.jp (H.H.) \\ 2 Fluid Mechanics and Energetics Dept., Ecole Centrale de Nantes, 44300 Nantes, France; AnjaSchnepf@web.de \\ 3 TPN-Numerical Offshore Tank Laboratory, Dept. of Naval Architecture and Ocean Engineering, \\ University of São Paulo, São Paulo 05508-030, Brazil; lucas.carmo@usp.br \\ 4 OSPL-Ocean Space Planning Laboratory, Dept. of Ocean Technology, Policy, and Environment, \\ The University of Tokyo, Chiba 277-0882, Japan; hirabayashi@k.u-tokyo.ac.jp \\ 5 Advanced Offshore Technology Dept., NMRI-National Maritime Research Institute, Tokyo 181-0004, Japan; \\ haneda@m.mpat.go.jp (K.H.); chujo@m.mpat.go.jp (T.C.) \\ 6 Marine Hydrodynamics Laboratory, Dept. of Aerospace and Marine System Engineering, \\ Osaka Prefecture University, Osaka 599-8531, Japan; nihei@marine.osakafu-u.ac.jp \\ 7 Technomar Engenharia Oceânica, São Paulo 05419-905, Brazil; edgard@technomar.com.br \\ * Correspondence: goncalves@g.ecc.u-tokyo.ac.jp; Tel.: +81-3-5841-0480
}

Received: 25 September 2020; Accepted: 20 October 2020; Published: 26 October 2020

check for updates

\begin{abstract}
A floating offshore wind turbine (FOWT) concept with a guy-wire-supported tower was investigated to obtain motion results in waves considering its elastic model characteristics. The FOWT concept studied aims to reduce the construction costs by using a light-weight structure tensioned with guy wires and a downwind type. Wave tank experiments of an elastically similar segmented backbone model in the 1:60 scale were carried out to clarify the dynamic elastic response features of the structure. The experimental results were compared with numerical simulations obtained from NK-UTWind and WAMIT codes. The bending moment measured the tower and pontoons had two peak values for different wave periods carried out. The short-wave period peak was due to sagging/hogging when the wavelength matched the floater length. The second peak was due to the large tower top acceleration, which caused a large bending moment at the tower base and pontoon to support the inertia force. The wind force was not significant to modify the FOWT response. The sensibility analysis in pontoons and tower rigidities confirmed the importance of the guy wires to support the inertia due to the waves and wind incidence. The new concept of a very-light FOWT with a guy-wire-supported tower may be an option for future FOWT developments.
\end{abstract}

Keywords: floating offshore wind turbine (FOWT); elastic characteristics; guy wires; wave tests

\section{Introduction}

Offshore wind has enormous potential since it allows the use of more constant and stronger winds. Large turbines could be used as there is no problem of visual pollution and noise generation. However, offshore wind cons lie in high costs for installation, mooring lines, and transmission cables.

New floater types, mooring systems, construction technologies have been investigated nowadays around the world. Light structures simple to build and easy to install are essential to minimize 
costs. As an example, in recent years in Japan, the NEDO (New Energy and Industrial Technology Development Organization) by "Next Generation Floating Offshore System-Demonstration Offshore Wind Farm" project adopted many solution concepts as a barge [1,2], semi-submersibles (SS) [3-6], and spar type $[7,8]$ floaters aiming for further cost reduction and wind farm developments as the Fukushima Floating Offshore Wind Farm Demonstration Project [9-11].

In this context, a new idea of a floating offshore wind turbine (FOWT) has been proposed. The conceptual idea consists of an arrangement with a central tower connected by pontoons to three columns by an angle of 120 degrees, as depicted in Figure 1. The columns are connected to the central tower by wires to reinforce the floating unit's structural strength, allowing the tower and the other structures to be lighter. These wires, referred to as guy wires in this paper, add stability to the standing tower and can be connected to the center of the columns. Due to the light structural characteristic, the pontoons, columns, and tower are subjected to hydro-elastic effects due to a decrease in rigidity, which requires evaluating the forces and deformations due to the waves on the various structural elements.

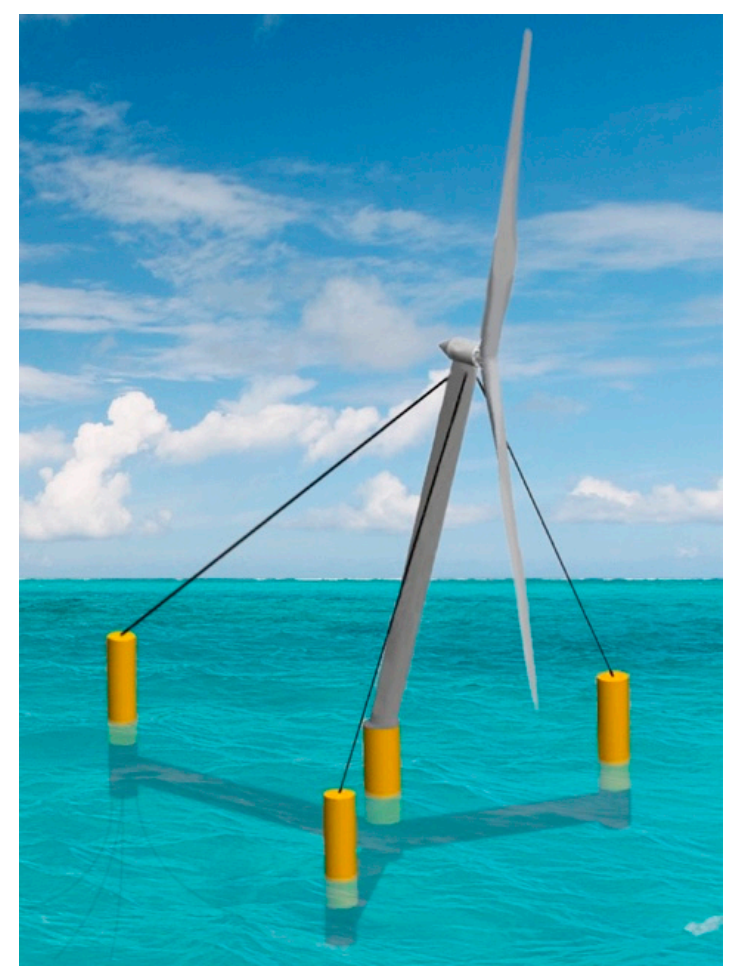

Figure 1. Conceptual idea of the floating offshore wind turbine (FOWT) with guy wires and light-weight structure.

An example of dynamic and elastic behavior investigations on a light-weight semi-submersible floater using a finite element model (FEM) code can be found in [12]. A very light SS floater with guy wires and a straight tower was investigated prior in 2017 by the University of Tokyo (UTokyo), Japan, and the model tests were performed at the University of São Paulo (USP), Brazil. The work was described in [13-15], where the experimental results were compared with numerical simulations to investigate the floater's elastic and dynamic responses. The results confirmed a feasible behavior in waves of an FOWT with the guy wires as an option to reduce costs. From the previous results, the structure was modified. The present work includes geometric modifications on the floater as a non-symmetric platform, an inclined tower, and a turret mooring system. The improvements and detailed performance are presented in this work. Preliminary results in regular waves only were presented in [16]. 


\section{Experimental Setup}

\subsection{Reduced Scale Model}

A reduced scale model was constructed to be elastically and dynamically similar to the prototype characteristics to clarify the floater's response characteristics in waves. The reduced-scale model 1:60 is shown in Figure 2.

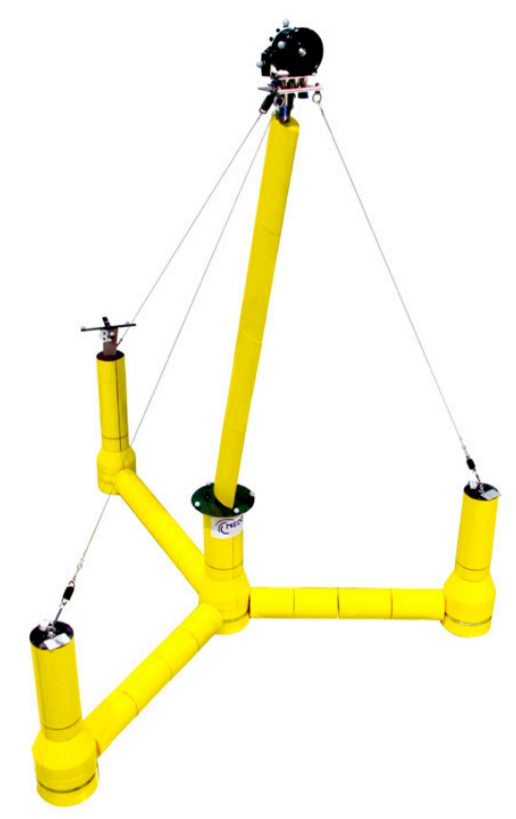

Figure 2. Elastic and dynamic similar segmented backbone model used in the experiments.

Table 1 shows the scale factors applying the Froude law for selecting the reduced scale model properties. Core stainless (SUS304) beams were used to represent the elastic similarity of the model (providing the structural rigidity), and the urethane pieces were wrapped around the core beams to represent the geometric similarity. Urethane parts were segmented to avoid additional stiffness due to material. The main model dimensions are summarized in Table 2. Table 3 shows the main hydrostatic and structural characteristics of the floater.

Table 1. Scale factors using Froude scaling.

\begin{tabular}{cc}
\hline Characteristic & Scale Factor \\
\hline length $(\mathrm{m})$ & $\lambda$ \\
time $(\mathrm{s})$ & $\lambda^{\frac{1}{2}}$ \\
force $(\mathrm{N})$ & $\lambda^{3}$ \\
mass $(\mathrm{kg})$ & $\lambda^{3}$ \\
flexural rigidity $E I\left(\mathrm{~N} \cdot \mathrm{m}^{2}\right)$ & $\lambda^{5}$ \\
\hline
\end{tabular}

Table 2. Main dimensions of the floater.

\begin{tabular}{ccc}
\hline Dimension & Prototype Full Scale & Model Scale (1:60) \\
\hline length & $90.00 \mathrm{~m}$ & $1500 \mathrm{~mm}$ \\
breadth & $93.00 \mathrm{~m}$ & $1550 \mathrm{~mm}$ \\
height to nacelle & $109.80 \mathrm{~m}$ & $1830 \mathrm{~mm}$ \\
draft & $14.75 \mathrm{~m}$ & $250 \mathrm{~mm}$ \\
\hline
\end{tabular}


Table 3. Main properties of the floater.

\begin{tabular}{ccc}
\hline Property & Prototype Full Scale & Model Scale 1:60 \\
\hline displacement & $7194 \mathrm{ton}$ & $33.3 \mathrm{~kg}$ \\
KB & $5.23 \mathrm{~m}$ & $87.2 \mathrm{~mm}$ \\
BM (roll/pitch) & $15.92 / 17.07 \mathrm{~m}$ & $265.3 / 284.6 \mathrm{~mm}$ \\
KG & $12.96 \mathrm{~m}$ & $215.9 \mathrm{~mm}$ \\
GM (roll/pitch) & $9.35 / 8.20 \mathrm{~m}$ & $155.9 / 136.6 \mathrm{~mm}$ \\
E core material & $2.06 \times 10^{11} \mathrm{~Pa}$ & $2.06 \times 10^{11} \mathrm{~Pa}$ \\
water depth & $55.80 \mathrm{~m}$ & $933 \mathrm{~mm}$ \\
\hline
\end{tabular}

In the reduced-scale model, guy wires were made by strained steel cables. A pre-tension of $21 \mathrm{~N}$ was imposed on the front guy wire (T1) and 12N on the side guy wires (T2 and T3); see Figure 3 for details. A turret was located in the column positioned windward. The turret allows the free yaw motions, i.e., the yaw stiffness and damping can be neglected. The mooring system was attached to the turret point.

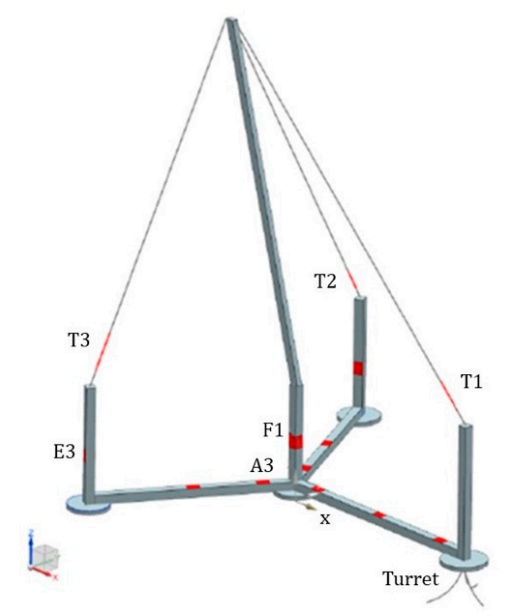

Figure 3. Location of the strain gauges and tension meters in the experimented model.

The model was equipped with eleven pairs of strain gauges to measure the bending moment of the tower, pontoons, and columns. The gages were located on the inner metal beam frame of the model, as presented in Figure 3. The guy wires have a tension meter at their bottom, and the tension meters of the mooring lines were located directly under the turret.

A ducted fan was implemented on the model at the turbine nacelle to simulate the floating body response experimentally when wind loads were applied. A sketch of the duct fan is presented in Figure 4.

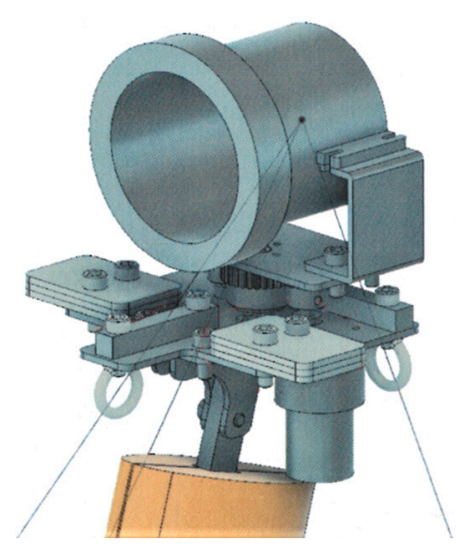

Figure 4. Sketch of the ducted fan. 
A catenary mooring located in the turret position, including chain and wires with different weight characteristics, was adopted, with an angle of 120 degrees for each line. The details of each mooring segment are presented in Table 4.

Table 4. Mooring system properties in the full scale.

\begin{tabular}{ccccc}
\hline Material & Length $(\mathbf{m})$ & $\begin{array}{c}\text { Chain Diameter } \\
(\mathbf{m})\end{array}$ & $\begin{array}{c}\text { Weight in Air } \\
(\mathbf{k N} / \mathbf{m})\end{array}$ & $\begin{array}{c}\text { Weight in Water } \\
(\mathbf{k N} / \mathbf{m})\end{array}$ \\
\hline chain & 60.00 & 0.208 & 3.42 & 2.97 \\
chain with weights & 100.00 & 0.208 & 13.40 & 11.70 \\
wire & 400.00 & 0.150 & 0.82 & 0.70 \\
chain & 50.00 & 0.208 & 3.42 & 2.97 \\
\hline
\end{tabular}

\subsection{Tank and Environmental Conditions}

The experiments were conducted at the Ocean Engineering Basin in the National Maritime Institute (NMRI), Japan. The tank has dimensions of $27 \mathrm{~m} \times 40 \mathrm{~m} \times 0.93 \mathrm{~m}$ (width, length, depth) and is equipped with a piston-type wavemaker. The top view schematic of the setup is presented in Figure 5 . The water depth was adjusted to be similar to the real conditions in the model scale, i.e., $55.8 \mathrm{~m}$ in the full scale representing a shallow water condition.

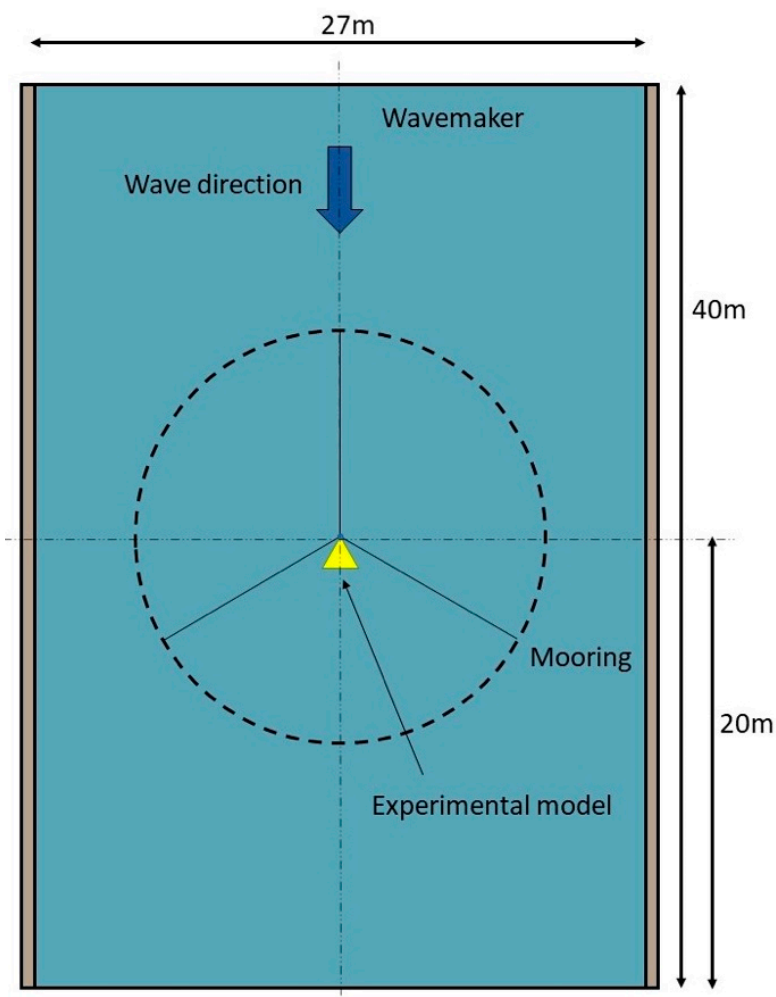

Figure 5. Top view of the wave basin setup.

The 6-degrees-of-freedom (dof) motions of the model were measured using the Qualisys ${ }^{\circledR}$ optical motion capture system. Four tracking cameras were used, and the sampling frequency was $100 \mathrm{~Hz}$.

A wave probe was positioned at the front of the main carriage during the experiments. Additionally, the four optical tracking cameras were set on the main carriage.

Wave and wind loads were measured in this experiment; directions were as in Figure 6; however, this study focuses on the floater's motion behavior and elastic characteristics due to the wave incidence. 


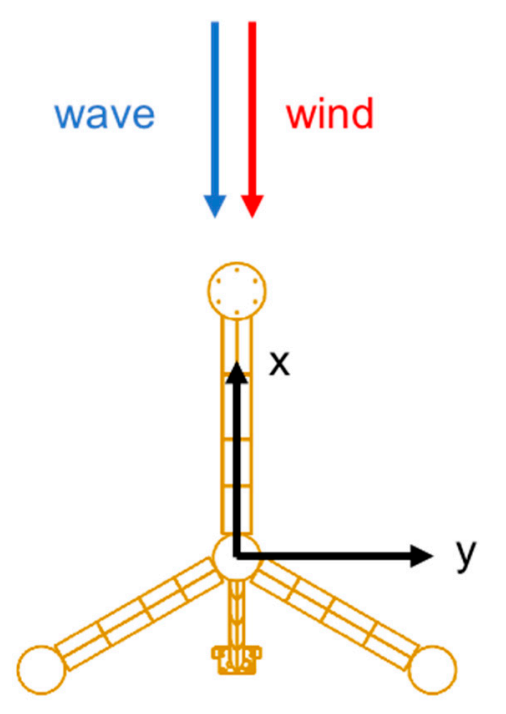

Figure 6. Wave and wind angle incidences.

\subsubsection{Wave Conditions}

Irregular and regular wave tests were carried out, and the parameters are presented in Tables 5 and 6, respectively:

Table 5. Irregular wave condition parameters in the full scale using the International Ship and Offshore Structures Congress (ISSC) spectrum.

\begin{tabular}{ccc}
\hline Condition & Significant Height $H_{\boldsymbol{s}}(\mathbf{m})$ & Period of Peak $\boldsymbol{T}_{\boldsymbol{p}}(\mathbf{s})$ \\
\hline operational & 2.5 & 9.0 \\
storm & 9.6 & 13.5 \\
centenary & 4.0 & 16.1 \\
\hline
\end{tabular}

Table 6. Regular wave condition parameters in the full scale.

\begin{tabular}{ccc}
\hline Condition & Regular Wave Height $\boldsymbol{H}_{\boldsymbol{r}}(\mathbf{m})$ & Range of the Wave Period (s) \\
\hline low & 1.8 & $4.6-29.4 \mathrm{~s}$ \\
medium & 3.6 & $9.3-17.0 \mathrm{~s}$ \\
high & 5.4 & $9.3-17.0 \mathrm{~s}$ \\
\hline
\end{tabular}

\subsubsection{Wind Conditions}

Two tests were performed with different wind speeds to consider the loads in the whole platform, as presented in Table 7. Thereby, the ducted fan simulated the sum of the drag due to the wind incidence acting on each part of the floating body below the nacelle and the turbine's thrust force. The relative velocity between the wind and platform motions was taken into account using dynamic control of the ducted fan's thrust force. The wind conditions were performed with the regular wave conditions to evaluate the wind effect on the platform response.

Table 7. Wind speed conditions in the full scale.

\begin{tabular}{cc}
\hline Condition & Wind Speed $U(\mathrm{~m} / \mathrm{s})$ \\
\hline maximum operational & 11.0 \\
typhoon & 41.9 \\
\hline
\end{tabular}




\section{Numerical Methods}

\subsection{NK-UTWind Code Model}

First, the full-scale FOWT was numerically modeled and analyzed using NK-UTWind code (an in-house code developed by The University of Tokyo for coupled analysis of FOWT).

In the analysis code, the rotor and floating body were modeled as beam elements; the mooring system was modeled using the quasi-static catenary mooring method; however, the lumped mass method was also an alternative. For calculating the aerodynamic load acting on the rotor, the wind turbine analysis code, FAST [17], based on the blade element momentum theory developed by NREL (National Renewable Energy Laboratory), was used. A complete description of the method implemented in NK-UTWind can be found in [18]. See an example of the mesh in Figure 7.

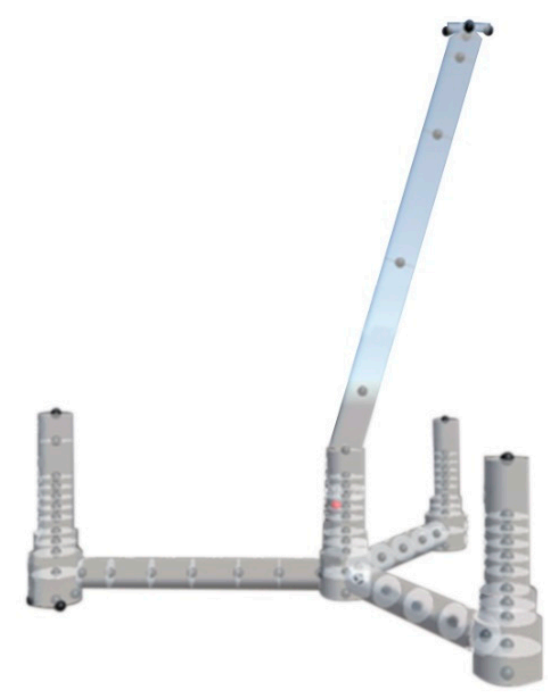

Figure 7. Mesh and nodes considered in the NK-UTWind code analysis.

As most FOWTs are comprised of slender structural elements such as cylinders, NK-UTWind employs the Morison equation for the evaluation of the hydrodynamic loads, as represented by the following equations:

$$
\left[\begin{array}{l}
d F_{x} \\
d F_{y}
\end{array}\right]=\rho A\left[\begin{array}{l}
\left(1+C_{a x}\right) \dot{u}_{x} \\
\left(1+C_{a y}\right) \dot{u_{y}}
\end{array}\right]-\rho A\left[\begin{array}{c}
C_{a x} \dot{v}_{x} \\
C_{a y} \dot{v}_{y}
\end{array}\right]+\frac{1}{2} \rho D|u-v|\left[\begin{array}{c}
C_{d x}\left(u_{x}-v_{x}\right) \\
C_{d y}\left(u_{y}-v_{y}\right)
\end{array}\right]
$$

where $\rho$ is the fluid density, $A$ is the cross-sectional area, $u_{x}$ and $u_{y}$ are water particle velocities in $x$ and $y$-direction. $v_{x}$ and $v_{y}$ are velocities of the structural element in $x$ and $y$-direction in the global coordinate system. $C_{a x}$ and $C_{a y}$ are the added mass coefficients in $\mathrm{x}$ and y-direction. $C_{d x}$ and $C_{d y}$ are drag force coefficients in $x$ and $y$-direction. The Wheeler's stretching method is used to estimate the wave velocity field, and the instantaneous wave load is evaluated considering the submergence of each structural element; see details in [19].

The added mass coefficients and drag coefficients for each element were obtained from DNV-GL guidelines [20] as standard hydrodynamic coefficients for cylinders.

NK-UTWind is a non-linear time-domain code. The height of the regular wave simulated must be input. The regular wave height of $1.8 \mathrm{~m}$ (low wave height condition) was chosen to avoid the non-linearities and provide a better comparison with further WAMIT simulations.

\subsection{WAMIT Code Model}

Besides the analysis performed with NK-UTWind code, the behavior of the FOWT was also evaluated using the WAMIT code, a commercial Boundary Element Method (BEM) code for analyzing 
wave interactions with offshore structures. The code evaluates the hydrodynamic loads through the radiation/diffraction problem in the frequency domain. Since WAMIT code calculations applied a different method than those employed in NK-UTWind, comparing the motion of the response amplitude operators (RAOs) obtained with both software indicates how conditions each methodology is better at reproducing the experiments.

The WAMIT simulation was performed on the full scale with a low-order mesh composed of 4654 flat quadrilateral and triangular panels with a mean edge length of approximately $1.3 \mathrm{~m}$ in full scale, as illustrated in Figure 8.

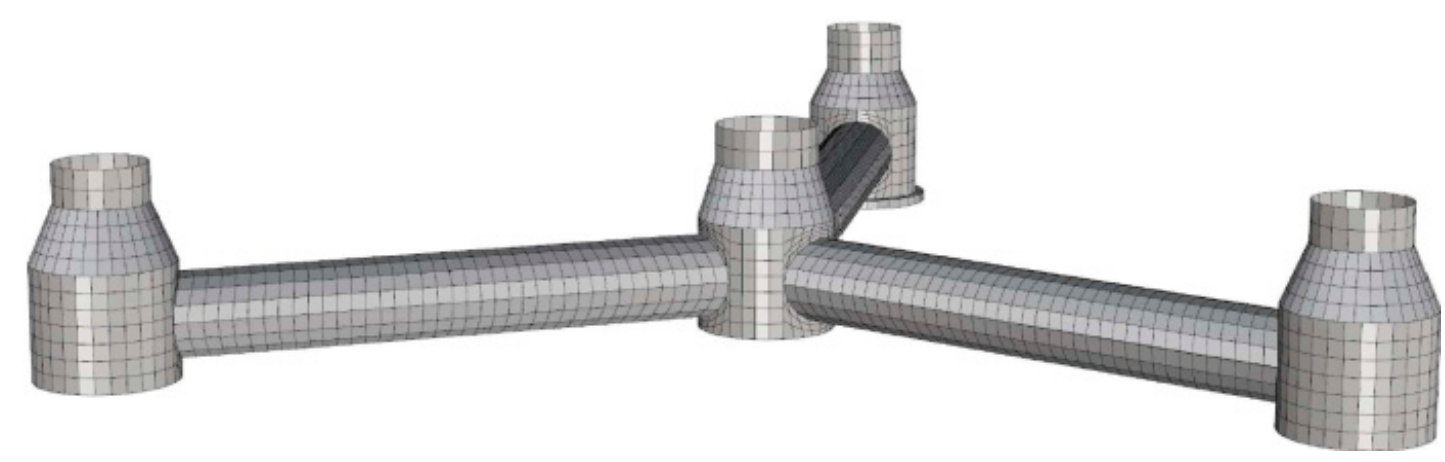

Figure 8. Low-order mesh considered in the WAMIT code analysis.

Since WAMIT is based on the potential flow and mooring lines are not directly modeled in the code, it is necessary to include an external linear stiffness matrix to partially model mooring effects. The mooring line characteristics were included in the software Edtools ${ }^{\circledR}$ that calculated the full stiffness matrix using the formulation presented in [21], the non-diagonal terms due to the degree-of-freedom coupling was also considered. The sketch of the mooring lines setup is illustrated in Figure 9. The characteristics of the mooring lines were the same as those presented previously in Table 4 . The full external matrix calculated as the described procedure and considered in the WAMIT code analysis is shown in Table 8.

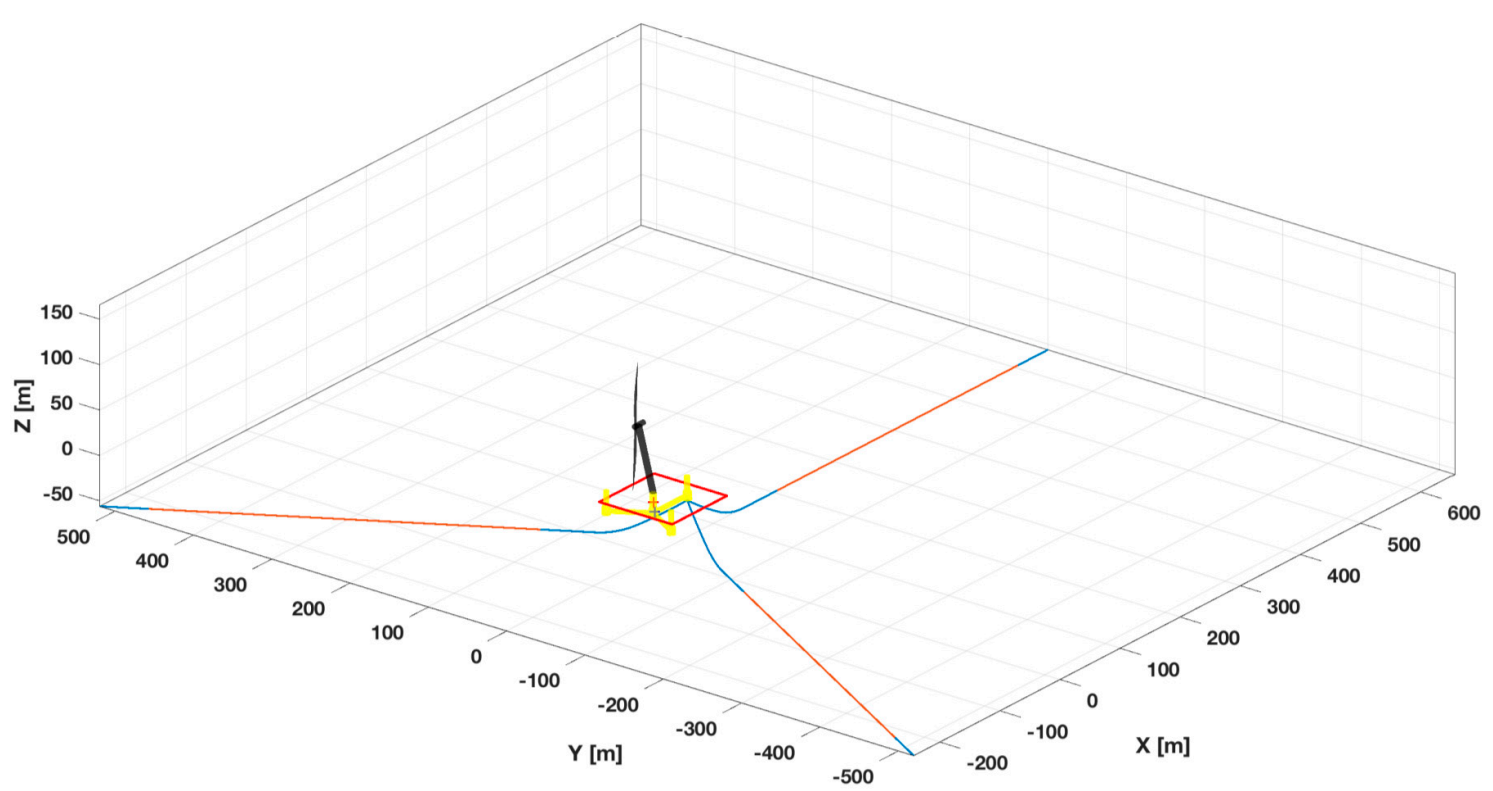

Figure 9. 3D view of mooring lines setup by Edtools ${ }^{\circledR}$ software in the full scale. 
Table 8. External stiffness values considered in the WAMIT code analysis in the full scale ( $i$-index is the corresponding DOF as, $1=\operatorname{surge}(\mathrm{kN} / \mathrm{m}), 2=$ sway $(\mathrm{kN} / \mathrm{m}), 3=$ heave $(\mathrm{kN} / \mathrm{m}), 4=\operatorname{roll}(\mathrm{kN} . \mathrm{m} / \mathrm{rad})$, $5=$ pitch $(\mathrm{kN} . \mathrm{m} / \mathrm{rad})$, and $6=$ yaw $(\mathrm{kN} . \mathrm{m} / \mathrm{rad}))$.

\begin{tabular}{ccccccc}
\hline $\boldsymbol{K}_{\boldsymbol{i i}}$ & $\mathbf{1}$ & $\mathbf{2}$ & $\mathbf{3}$ & $\mathbf{4}$ & $\mathbf{5}$ & $\mathbf{6}$ \\
\hline 1 & $4.69 \times 10^{2}$ & 0 & 0 & $-2.40 \times 10$ & $-1.49 \times 10^{2}$ & $-8.14 \times 10$ \\
2 & 0 & $4.70 \times 10^{2}$ & 0 & $8.24 \times 10^{3}$ & 0 & $2.74 \times 10^{4}$ \\
3 & 0 & 0 & $1.97 \times 10^{2}$ & $3.31 \times 10$ & $-1.15 \times 10^{4}$ & 0 \\
4 & $-2.40 \times 10$ & $8.24 \times 10^{3}$ & $3.31 \times 10$ & $1.79 \times 10^{5}$ & $-1.82 \times 10^{3}$ & $4.80 \times 10^{5}$ \\
5 & $-1.49 \times 10^{2}$ & 0 & $-1.15 \times 10^{4}$ & $-1.82 \times 10^{3}$ & $6.70 \times 10^{5}$ & -1.28 \\
6 & $-8.14 \times 10$ & $2.74 \times 10^{4}$ & 0 & $4.80 \times 10^{5}$ & -1.28 & $1.60 \times 10^{6}$ \\
\hline
\end{tabular}

The diagonal values of the damping matrix were first obtained from the experimental decay test results. The values were $\zeta_{33}=12 \%$ and $\zeta_{55}=10 \%$ for heave and pitch, respectively. As the system's degrees of freedom are strongly coupled due to the turret mooring line configuration, it was necessary to include non-diagonal terms in the damping matrix. Due to the high sensitivity to this parameter, two different values were tested as $\zeta_{35}=\zeta_{53}=-0.2 \%$ and $\zeta_{35}=\zeta_{53}=-0.5 \%$; these values are in terms of the critical damping value of pitch.

\section{Results}

The main results obtained from the experiments and NK-UTWind code calculations were the first-order motions of the floater, bending moments at different locations on the structure, and the tension fluctuations in the guy wires. WAMIT code provided only results of first-order motions of the floater. The values were presented in the full scale.

\subsection{Experimental and Numerical Motion Response in Waves}

Natural periods obtained from free decay tests are shown in Table 9, both from experiment and numerical calculation. The values inside the parentheses represent the period corresponding to the peak in the RAO, and outside the parentheses represent the natural period obtained from free decay tests.

Table 9. Comparison of measured and numerical natural periods.

\begin{tabular}{cccc}
\hline & Experiment (s) & NK-UTWind (s) & WAMIT (s) \\
\hline surge & 35.77 & 35.60 & $(36.00)$ \\
heave & $17.60(18.50)$ & 18.01 & $(16.50)$ \\
pitch & $21.98(22.67)$ & 24.01 & $(23.00)$ \\
\hline
\end{tabular}

The RAO results obtained from regular and irregular waves for surge, heave, and pitch are presented in Figures 10-12. Experimental and numerical results were plotted in the same graphic to show the comparison between them.

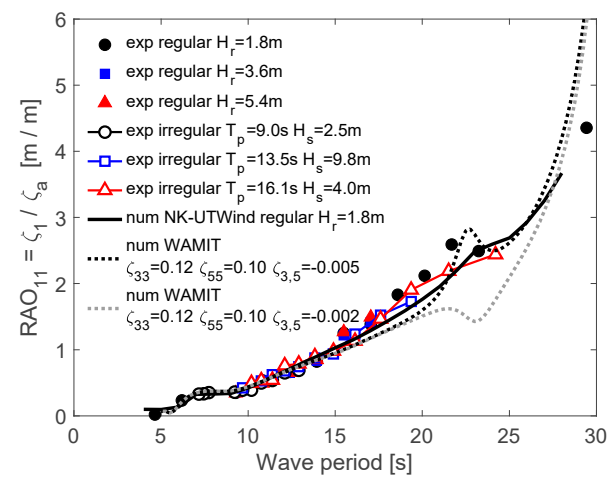

Figure 10. RAO surge motion result comparisons between the experiment and numerical calculations. 


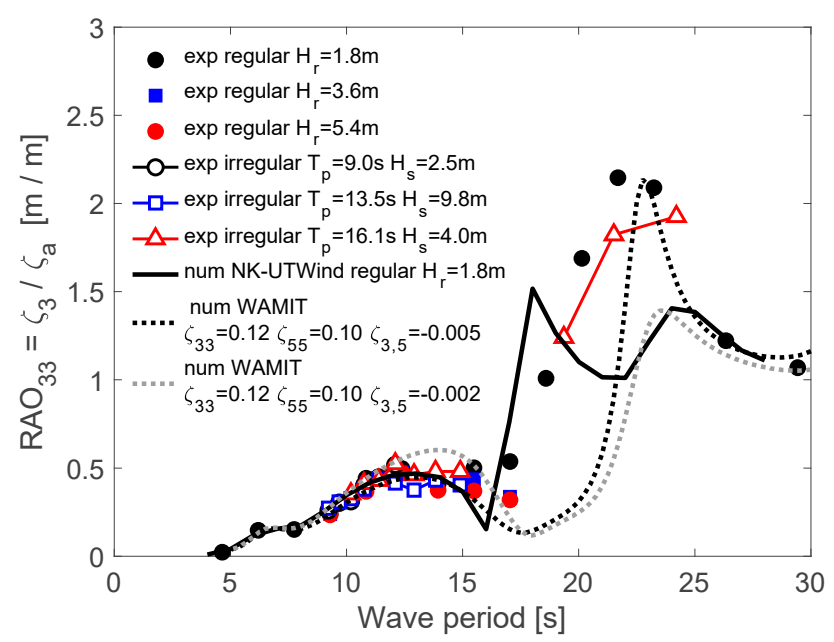

Figure 11. RAO heave motion result comparisons between the experiment and numerical calculations.

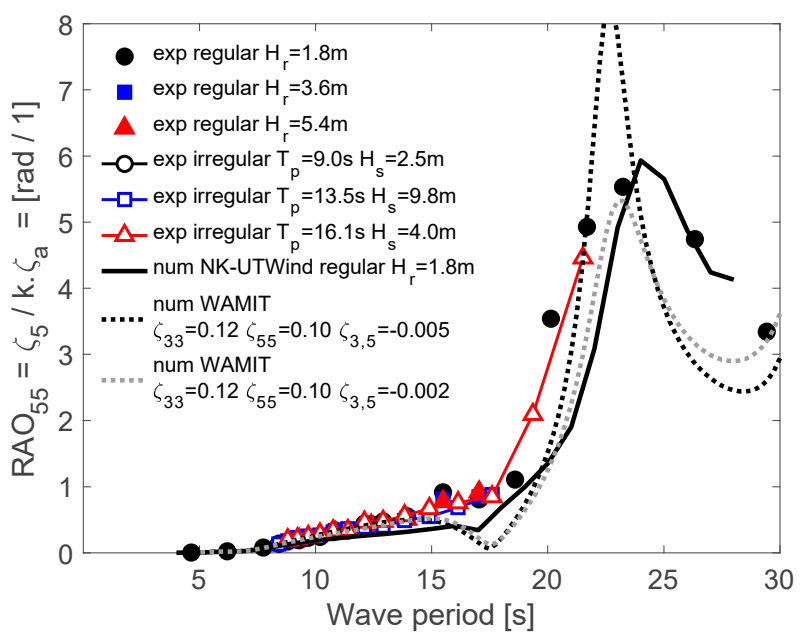

Figure 12. RAO pitch motion result comparisons between the experiment and numerical calculations.

In general, the experimental results from regular and irregular wave tests were similar for all degrees of freedom.

Figure 10 presents the RAO surge results. The experimental and numerical results agreed very well for short-period waves, $T<15 \mathrm{~s}$. Moreover, even for long-period waves, the comparison was good and showed the same qualitative behavior. Small differences could be observed around $22 \mathrm{~s}$ that represent the period of the pitch motion. The system presented a strong surge and pitch coupling due to the turret characteristic of the mooring lines. Numerical calculations using NK-UTWind code could observe the peak in the surge due to the pitch natural period, and the numerical results agreed well with the experiments. However, external damping in the cross-terms of the damping matrix should be added due to the coupling between the degrees of freedom in the WAMIT code calculations. The surge natural period was not visible in the RAO results because it is outside the range of periods calculated.

Figure 11 presents the RAO heave results. Small differences could be observed for experimental heave results around the heave natural period, $17 \mathrm{~s}$, because of the non-linear behavior of the damping by the different wave height incidences. The same behavior can be observed around the pitch natural period of $22 \mathrm{~s}$, which showed larger damping for the irregular wave case than for the lowest regular one.

The experimental RAO heave presented a typical behavior of the one obtained for multi-column semi-submersible type, that contains a cancelation point due to the ratio between center column distances, pontoon height, and incident wavelength. RAO heave converged to the unity for long-period 
waves, as expected. However, the heave resonance peak was not clear due to the cancelation point, and the heave resonance region was in the same range.

For this system, the coupling between heave and pitch was markable due to the turret characteristic. The coordinate system was located at the center of gravity of the platform; however, the center of rotation was shifted due to the turret presence, which explains the large coupling between these degrees of freedom. Therefore, the coupling between heave and pitch addressed the peak in the RAO heave around the pitch natural period of $22 \mathrm{~s}$.

It was possible to see different behavior from the NK-UTWind and WAMIT code calculations in the numerical models. As noted, the mooring lines affected a lot the behavior of very light systems, like in the present study. Some differences between NK-UTWind and WAMIT codes could probably be due to the difference in mooring settings for the numerical calculation. A single material quasi-static mooring was applied for NK-UTWind code with non-linear behavior; however, a linear matrix of stiffness was used for the WAMIT code.

For NK-UTWind code calculations, the agreement was very good for short-wave periods, $\mathrm{T}<15 \mathrm{~s}$. A cancelation point was observed around $16 \mathrm{~s}$, and two peaks located in the natural periods of heave and pitch. The range between 16 and $25 \mathrm{~s}$ was susceptible to damping levels (cancelation and resonance region); therefore, the limitation of the Rayleigh damping matrix applied to tune the motions individually in each degree of freedom was not successful.

For WAMIT code calculation, the external damping should be input as an external damping matrix. It was possible to observe that the crossed terms due to the coupling between heave and pitch strongly affected the peak values. The best calibrated external damping level for the cross term was $\zeta_{35}=\zeta_{53}=-0.005$, which implied an excellent agreement for short-wave periods, $\mathrm{T}<15$, and the same RAO heave value in the pitch natural period. However, the same cross damping level was not well calibrated for the RAO pitch, as presented in Figure 12. The WAMIT code results could not represent well the response between the periods 15 and $22 \mathrm{~s}$, due to the same reason of the cancelation point and resonance range.

Figure 12 presents the RAO pitch results. All the experiment results suggested the same behavior. A clear significant peak was found around the pitch natural period. The pitch motion was also coupled with the surge motion; due to this behavior, the RAO pitch should have a peak value at the surge natural period around $36 \mathrm{~s}$ before reaching the unity value for long-wave periods. The experiments were performed until $30 \mathrm{~s}$ and could not confirm it.

It was possible to see different behavior from the NK-UTWind and WAMIT code calculations in the numerical models. Numerical and experimental results agreed well in general, manly for short wave periods, with some differences regarding the width around the peak in the pitch natural period. Differences in the hydrodynamic damping from experiments and numerical calculations could explain the disagreement.

For both numerical codes, the damping level was chosen to achieve the pitch motion's peak value in the RAO results. For NK-UTWind code calculations, the damping level came directly from the Morison equation solution using the drag coefficients for well-known elements; however, the damping levels came from the external damping matrix for WAMIT code. As discussed before, it was possible to observe that for RAO pitch, the best calibrated crossed damping level was $\zeta_{3,5}=\zeta_{5,3}=-0.002$; that confirmed that a small difference in the damping level could imply a significant difference in the RAO peak responses.

Figure 13 shows the experimental acceleration results at the rotor and nacelle assembly (RNA) calculated as an absolute acceleration value due to the six-dof motions. At the wave period of $25 \mathrm{~s}$, acceleration at the tower top presented the most considerable value due to a peak in the pitch motion. The full line showed the $0.4 \mathrm{G}$ design limit acceleration of RNA for comparison. It was possible to conclude that the absolute values of the accelerations observed during the model tests were lower than the design limit. 


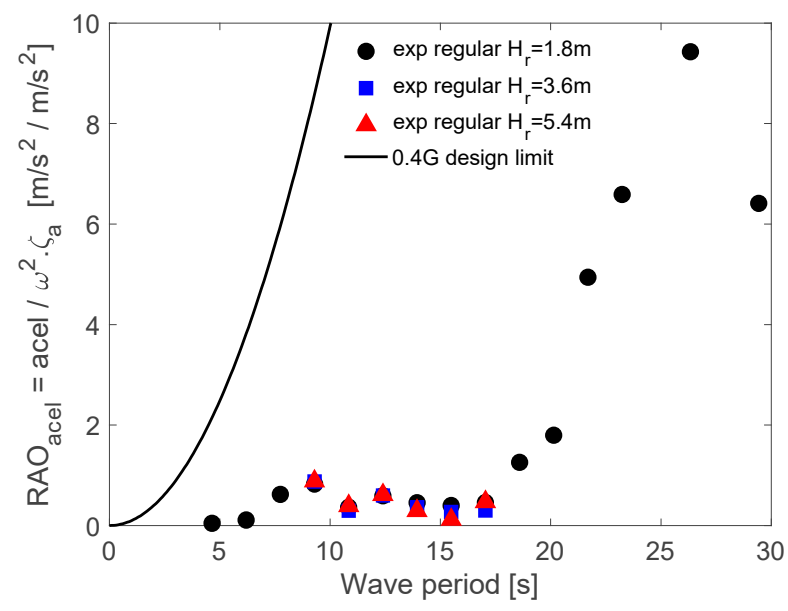

Figure 13. Experimental RAO acceleration results at the turbine nacelle.

\subsection{Experimental Motion Response in Waves and Wind}

The RAO results obtained from the lowest height regular wave for surge, heave, and pitch and wind presence are presented in Figures 14-16, respectively. Three conditions of incident wind speed were considered, as illustrated in Table 7, to verify the effects of the wind presence in the dynamic response in regular waves.

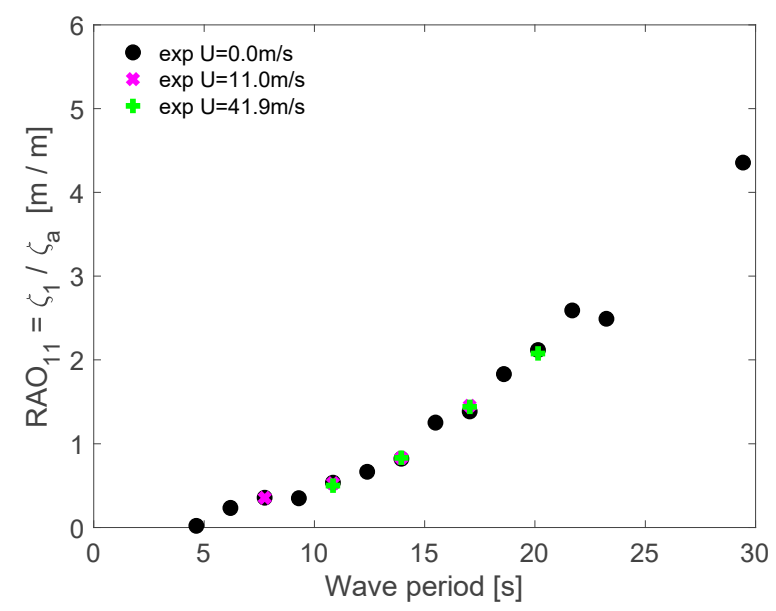

Figure 14. Effect of the incident wind speed on the experimental RAO surge motion results.

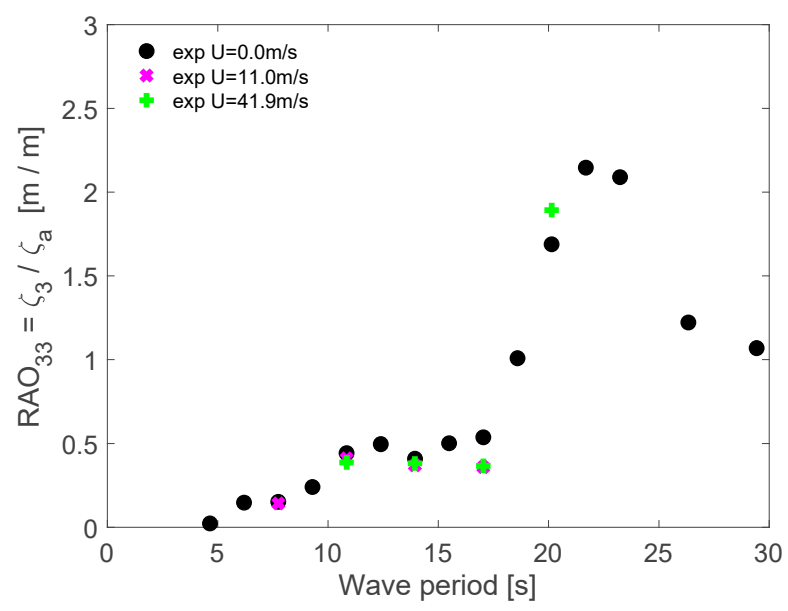

Figure 15. Effect of the incident wind speed on the experimental RAO heave motion results. 


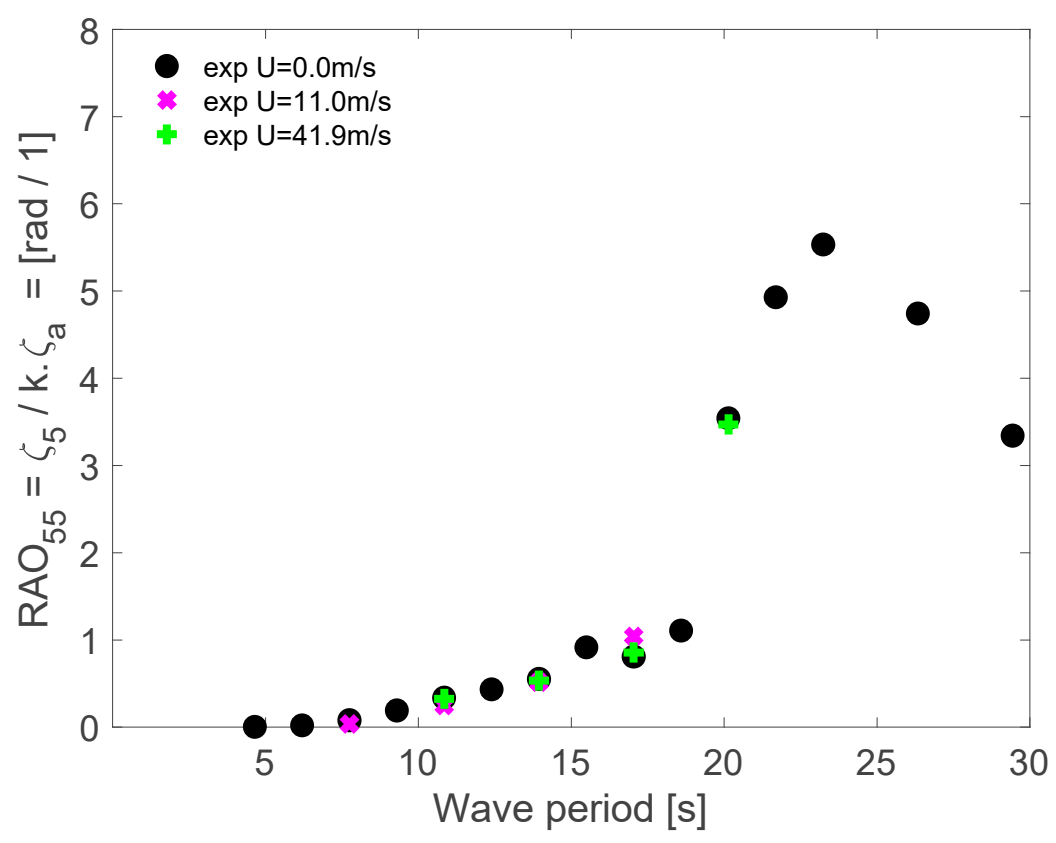

Figure 16. Effect of the incident wind speed on the experimental RAO pitch motion results.

In general, no differences were observed due to the incident wind in the platform's dynamic response. The difference occurred in the maximum inclination angle, as presented in Figure 17. The inclination angle increased due to the mean average moment caused by the wind presence; however, the maximum values were far from the operational limit of 15 degrees.

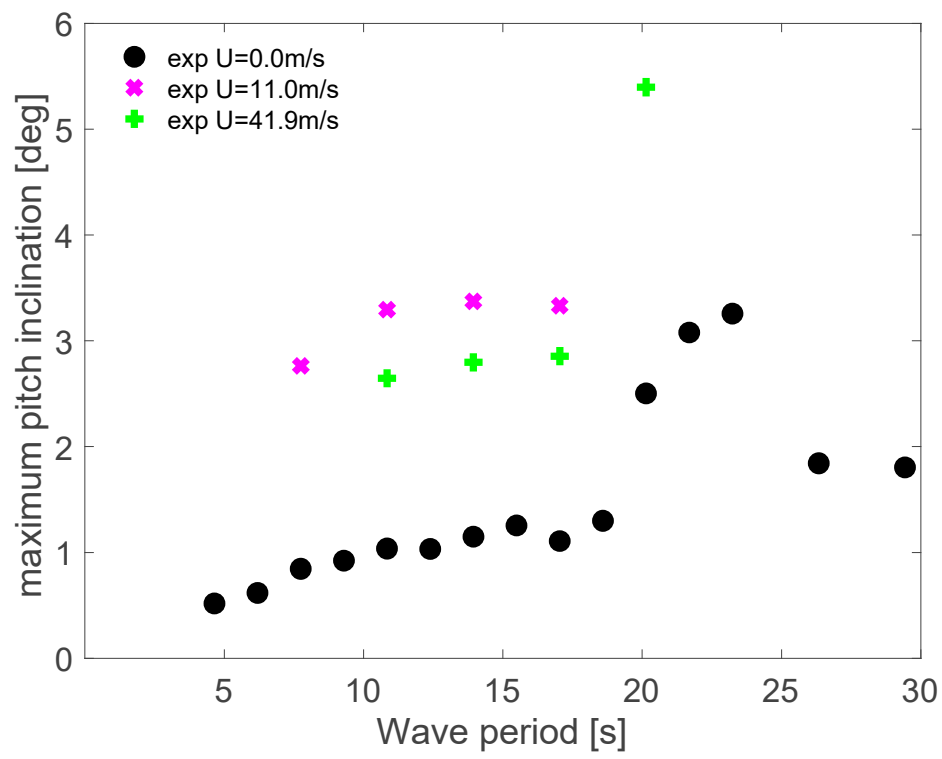

Figure 17. Effect of the incident wind speed on the experimental maximum pitch inclination angle results.

\subsection{Experimental Guy Wire Tensions, Tower and Pontoon Bending Moment Responses in Waves}

In general, no slack of the guy wires was observed during the experimental campaign. The behavior was confirmed by the monitored tension values, which were always positive; thus, the initial pre-tension was enough to keep the guy wires still working on tension. Moreover, the combination of the tower, pontoon arms, and guy wires seemed to hold the inertia force of the RNA at the tower top during all wave tests. 
Figures 18 and 19 present the experimental and numerical RAO tension results at the guy wires front (T1) and side (T3), respectively. Moreover, Figures 20-22 present the RAO bending moment at the tower base (F1), pontoon side gage (A3), and column side gage (E3) positions, respectively. For more details about the guy wires position, see Figure 3.

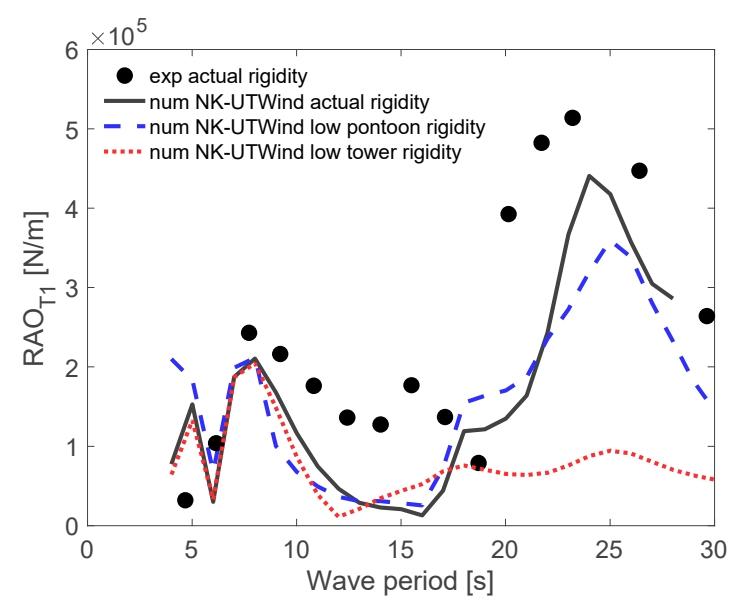

Figure 18. Influence of the tower and pontoon rigidities on the RAO tension result at the front guy wire (T1), and its comparison between the experiment and numerical calculation.

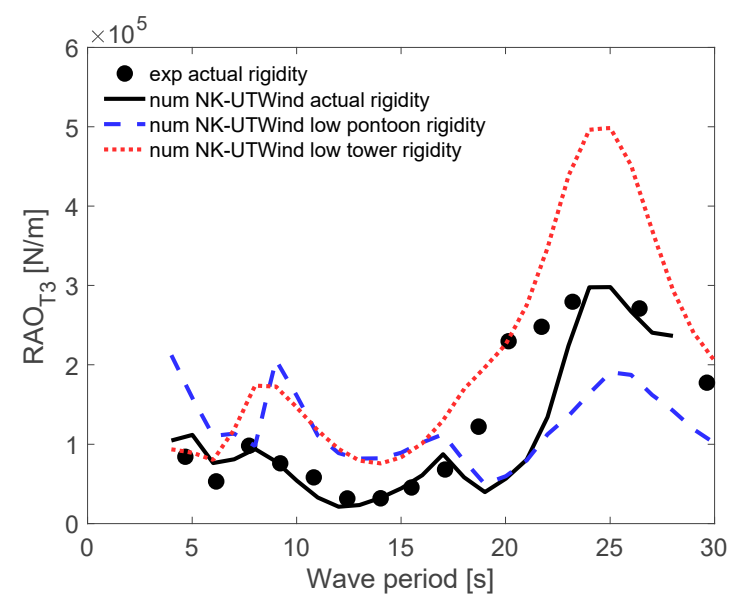

Figure 19. Influence of the tower and pontoon rigidities on the RAO tension result at the side guy wire (T3), and its comparison between the experiment and numerical calculation.

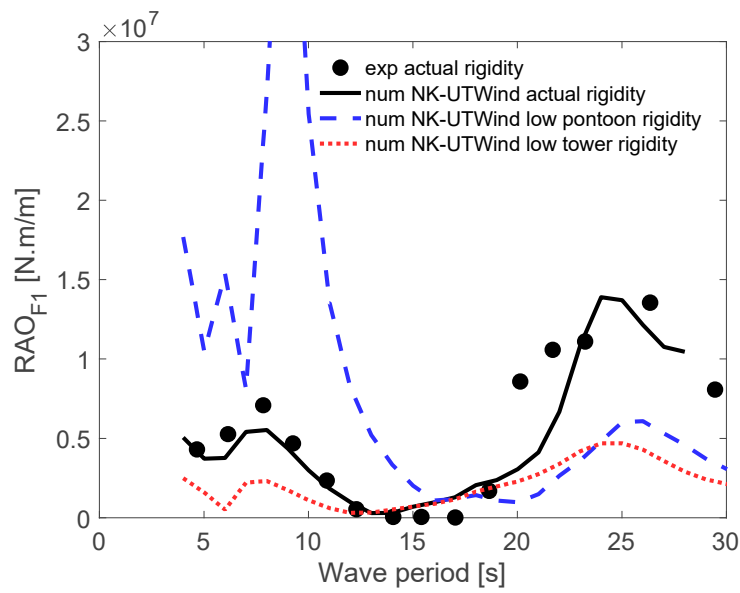

Figure 20. Influence of the tower and pontoon rigidities on the RAO bending moment at the tower-base gage (F1), and its comparison between the experiment and calculation. 


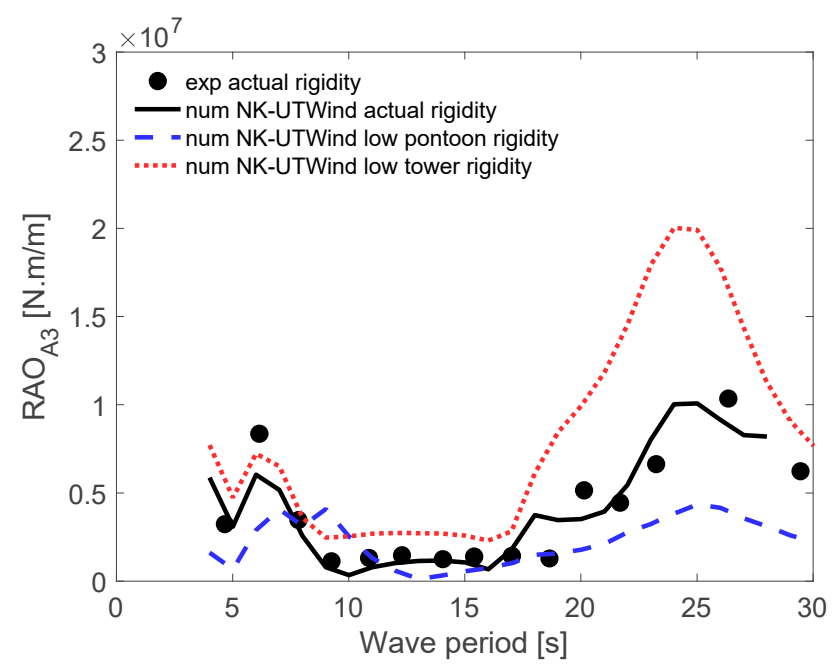

Figure 21. Influence of the tower and pontoon rigidities on the RAO bending moment at the side-pontoon gage (A3), and its comparison between the experiment and calculation.

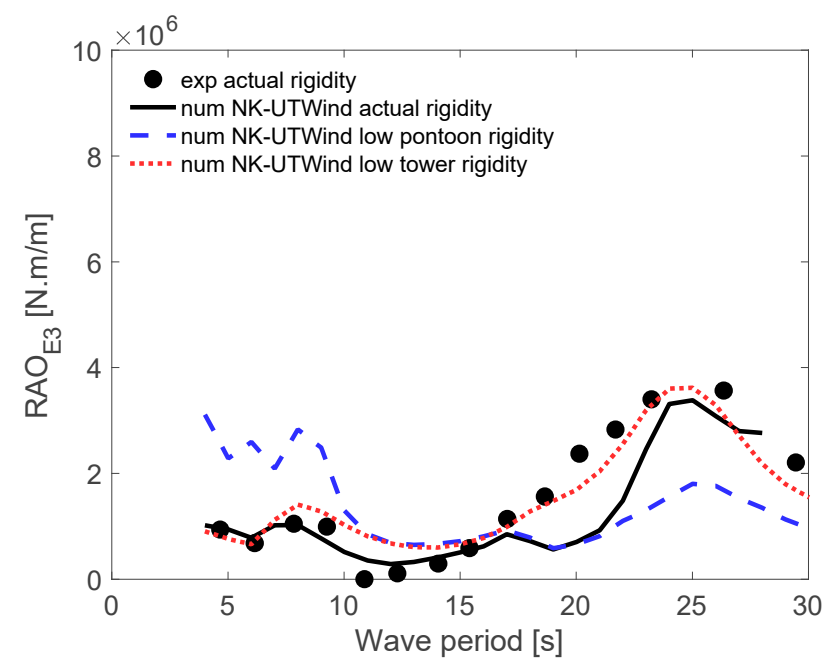

Figure 22. Influence of the tower and pontoon rigidities on the RAO bending moment at the side column gage (E3), and its comparison between the experiment and calculation.

In general, the force measurements comparison between experimental and numerical results from the NK-UTWind code showed a good qualitative agreement. Two peaks could be observed in all results. For the wave periods between 7 and $8 \mathrm{~s}$, the wavelength was equal to the distance between columns projected in the wave direction; thus, the sagging moment took maximum value when the wave crest came to the fore column and side column, and the wave trough was located around the central column. The highest peak observed around the wave periods between 22 and $27 \mathrm{~s}$ occurred due to the large pitch motion response in this range of wave period.

It was possible to observe a small peak close to $17 \mathrm{~s}$ for the bending moment at the pontoon (A3) and the front guy wire (T3) in the numerical results. This behavior was due to the vertical motion observed around the heave natural period, and a large inertia force applied to the pontoon. There were local minimum points in $10 \mathrm{~s}$ and $16 \mathrm{~s}$ for pontoon bending moment, see Figure 21. The first peak was due to the combination of heave and pitch motion, related to a wavelength close to twice the platform diameter length. The second peak came from the wave cancellation period in the vertical direction, where heave motions took minimum value, and the inertia force due to motions was small. 


\subsection{Influence of the Platform Structural Rigidity on the Tension and Bending Moment Responses}

The influence of the rigidity of the tower column and pontoons were studied numerically using the NK-UTWind code. Three levels of rigidity were analyzed, as presented in Table 10. The changes of rigidity were done at the pontoon and/or tower column values.

Table 10. Rigidity level applied for pontoons and tower column compared with the actual model.

\begin{tabular}{ccc}
\hline Member & Pontoons & Tower Column \\
\hline actual rigidity & $E I$ & $E I$ \\
low tower rigidity & $E I$ & $E I / 20$ \\
low pontoon rigidity & $E I / 50$ & $E I$ \\
\hline
\end{tabular}

Figures 18-22 present the numerical result comparison of tension/bending moments at different positions of measurement as front guy wire (T1), side guy wire (T3), tower base (F1), side pontoon (A3), and side gage (A1), respectively, for different levels of rigidity at the pontoon and/or tower column.

Overall, the effect of pontoon rigidity was large for wave periods between 7 and 8 s; moreover, the impact of tower column rigidity was significant for wave periods between 25 and $26 \mathrm{~s}$.

In Figure 20, it is possible to observe that the deformation due to the sagging/hogging (moment) peak response was large around the wave period of 7 and $8 \mathrm{~s}$, and the bending moment at the tower base took ten times the value of the high rigidity model when the pontoon rigidity was decreased. Therefore, the pontoon rigidity needed to be ensured when applying light-weight towers. It is a fact that the tower base and guy wires supported the inertia force from tower and RNA, and the ratio of load transmission differs with tower inclination and tower rigidity.

Figures 18 and 19 show the RAO tension results at the front guy wire (T1) side guy wire (T3). RAO tension results at the side guy wire (T3) took considerable tension when the tower rigidity was decreased. The inertia force from the tower motion was transmitted through side guy wires and to the connecting external columns, indicating that the main load transmission path was through the side structures. This behavior was because side guy wires and pontoons were less significant than those at the front; therefore, presenting a large total rigidity.

\subsection{Effect of the Guy Wires Presence on the Tension and Bending Moment Responses}

The influence of the existence or not of the guy wires was studied numerically using the NK-UTWind code. Figures 23-25 present the effect of the guy wires presence on the RAO bending at the tower-base (F1), side pontoon (A3), and side pontoon (E3) gages, respectively.

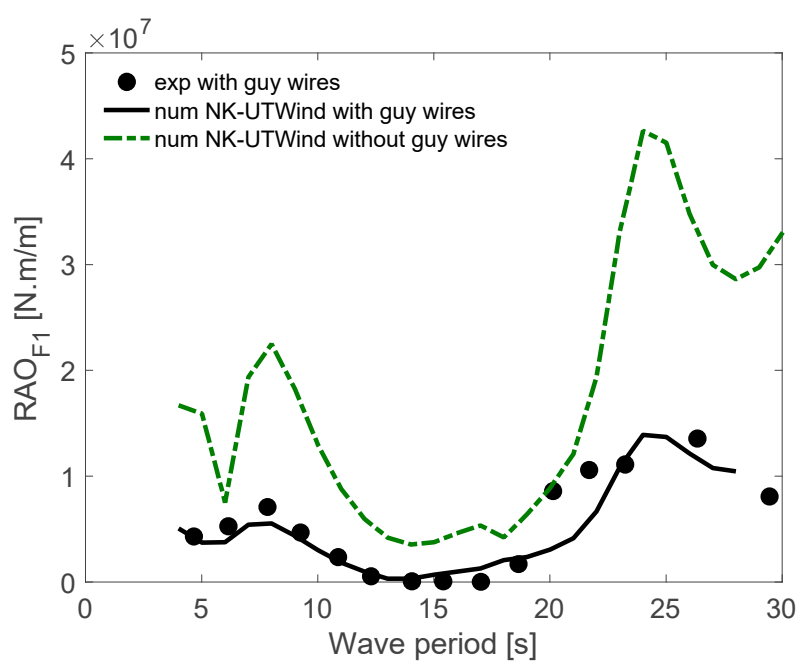

Figure 23. Effect of the guy wires on the RAO bending moment at the tower-base gage (F1), and its comparison between the experiment and calculation. 


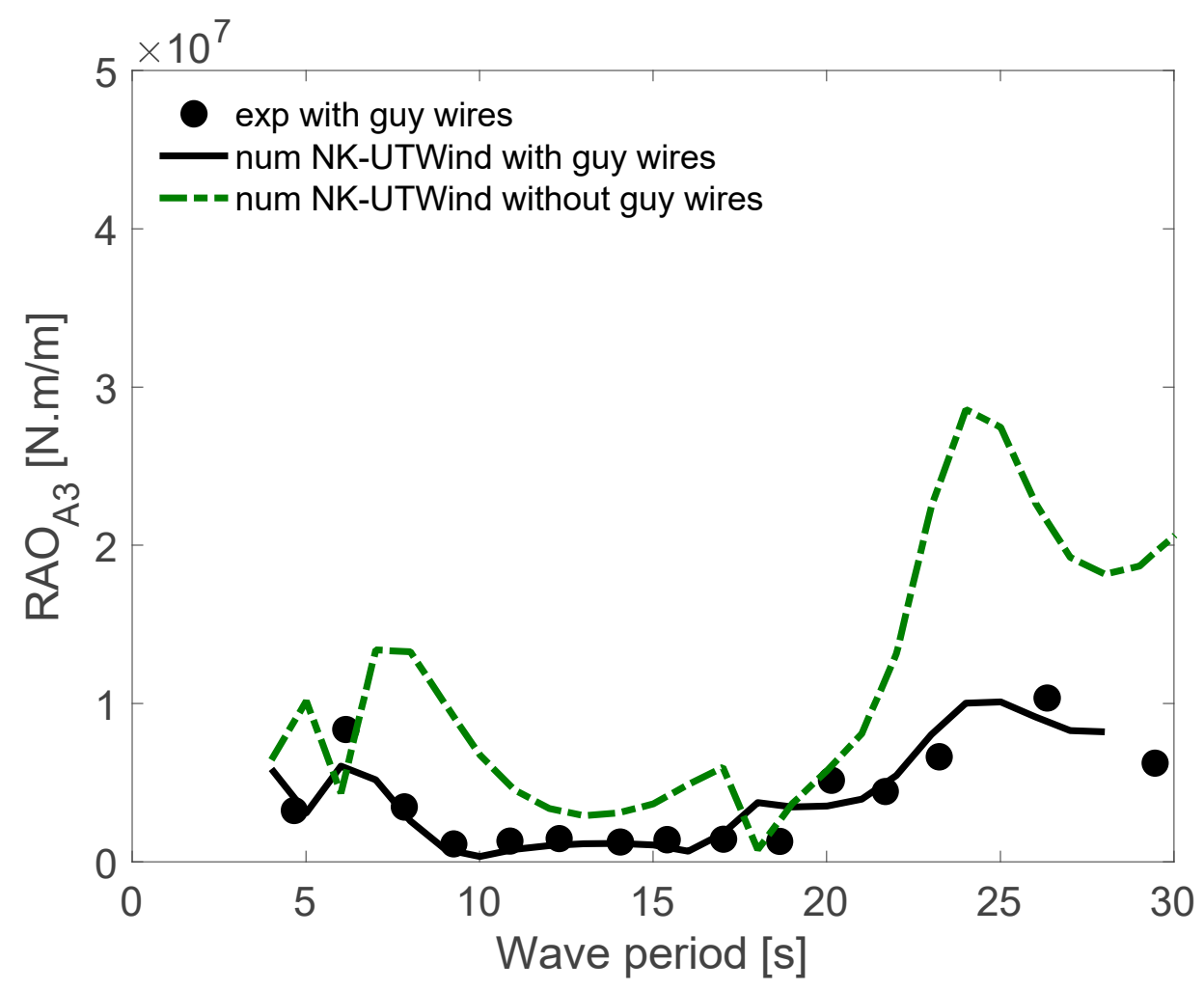

Figure 24. Effect of the guy wires on the RAO bending moment at the side pontoon gage (A3), and its comparison between the experiment and calculation.

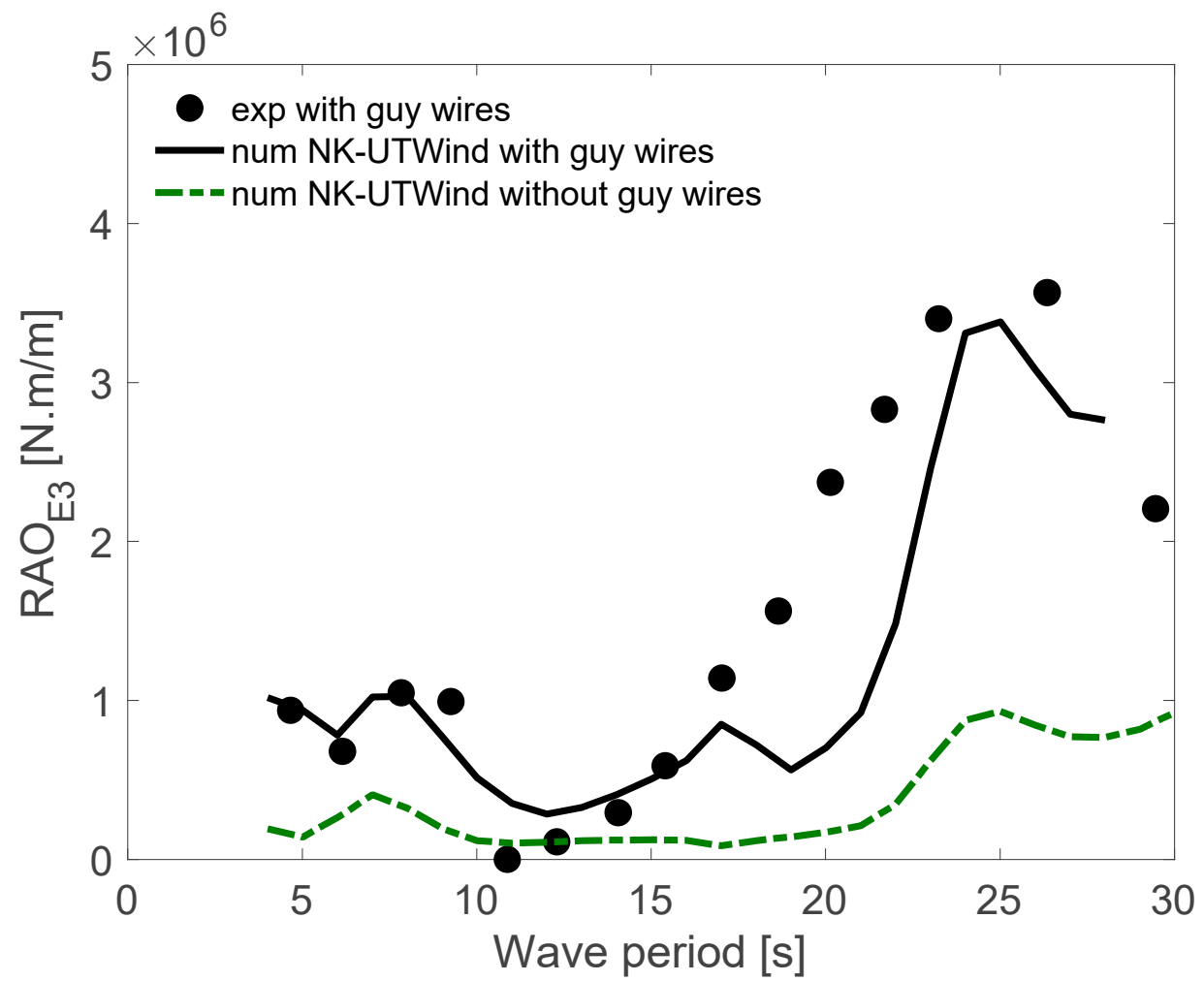

Figure 25. Effect of the guy wires on the RAO bending moment at the side column gage (E3), and its comparison between the experiment and calculation. 
As expected, the most significant bending moment without the guy wires was supported by the tower base (F1); see Figure 23, in which a maximum increase of four times occurred around the pitch natural period. Moreover, a significant increase in the bending moment happened at the side pontoon (A3) close to the tower base. Without the guy wires, the columns were not solicited to support the RNA; thus, the bending moment at the side column decreased for values lower than $10^{6} \mathrm{~N} \cdot \mathrm{m} / \mathrm{m}$, i.e., four times the maximum value.

\section{Conclusions}

This work presented an experimental wave and wind test campaign of a very-light FOWT with a guy-wired supported tower. Dynamic response characteristics were investigated by wave tank experiments with dynamic and elastic similar segmented backbone models. The motion and force responses were compared with numerical code results.

Regarding the dynamic response in waves, the structure's motion in the vertical direction showed typical response characteristics of a semi-submersible-type floating structure. The structure's overall motion was influenced mainly by heave and pitch motions, as a coupling between the degrees of freedom due to the turret characteristic of the mooring system. The wind presence did not affect the dynamic behavior of the platform.

The bending moment in the pontoons and tower base was large at a wave period of $7 \mathrm{~s}$ when the sagging moment took the maximum value due to the matching of wavelength and floater diameter. The guy wire tensions and the bending moment at the tower base and pontoons were large to support the inertia force when pitch motion was significant around the wave period of $26 \mathrm{~s}$.

The load-supporting function of guy wires was investigated by changing the rigidity of tower and pontoons. It was found that the inertia force due to tower motion was transmitted through side guy wires, external columns, and pontoons.

The effect of the guy wires' presence showed that the guy wire concept was significant and can be a useful alternative when designing very-light FOWT.

The maximum acceleration at the RNA and the maximum pitch inclination angles were lower than the limit of the design criteria; thus, the FOWT studied was feasible in hydrodynamic and structural behaviors. One of the limitations of this concept is the construction since the feasibility of introducing guy wires can be a problem and must be better evaluated.

Author Contributions: Conceptualization, H.S. (Hideyuki Suzuki) and Y.N.; methodology, R.T.G., H.H., K.H. and T.C.; software, H.H., K.H. and T.C.; validation, A.S., H.S. (Hiroki Shiohara), L.H.S.C. and E.B.M.; formal analysis, A.S. and H.S. (Hiroki Shiohara); investigation, A.S. and H.S. (Hiroki Shiohara); resources, K.H. and T.C.; data curation, K.H. and T.C.; writing-original draft preparation, A.S., H.S. (Hiroki Shiohara) and R.T.G; writing-review and editing, R.T.G.; supervision, R.T.G., H.H., S.H., Y.N. and H.S. (Hideyuki Suzuki); project administration, H.S. (Hideyuki Suzuki); funding acquisition, H.S. (Hideyuki Suzuki). All authors have read and agreed to the published version of the manuscript.

Funding: This research is based on the results obtained from a project commissioned by the New Energy and Industrial Technology Development Organization (NEDO), Japan.

Acknowledgments: This research is based on the results obtained from a project, JPNP14022, commissioned by the New Energy and Industrial Technology Development Organization (NEDO). The authors would like to thank NEDO for allowing the publication of the paper. The authors would like to thank the student Marques, M. A. from the Federal University of Pernambuco (UFPE), Brazil, for his help during the image developments; Ms. Matsui, R., and Eng. Nimura, T. from the National Maritime Research Institute (NMRI), Japan, and Hashimoto, K. from Osaka Prefecture University (OPU), Japan, for their assistance in carrying out experiments; and, Eng. Sakamoto, H. from Fractaly Co. Ltd., Japan, for model manufacturing and assembly. Prof. Gonçalves, R. T. thanks to the Japan Society for the Promotion of Science (JSPS) for the grant as JSPS International Research Fellow (P18355, Graduate School of Engineering, The University of Tokyo). The authors would like to acknowledge The Japan Society of Naval Architects and Ocean Engineers (JASNAOE) for the financial support of the internship period of the Brazilian researcher, Eng. Carmo, L. H. S., in Japan.

Conflicts of Interest: The authors declare no conflict of interest. 


\section{Nomenclature}

$\lambda$

scale factor

$\zeta \quad$ external damping factor coefficient

$\zeta_{1} \quad$ amplitude of the surge motion (m)

$\zeta_{3} \quad$ amplitude of the heave motion (m)

$\zeta_{5}$ amplitude of the pitch motion (rad)

$\zeta_{a} \quad$ amplitude of wave (m)

$A 3$ strain gage at the side-pontoon gage

$B$ buoyance center

$B M \quad$ metacentric radius (m)

$C_{a x} \quad$ added mass coefficient in the $\mathrm{x}$-direction

$C_{a y} \quad$ added mass coefficient in the y-direction

$C_{a z} \quad$ added mass coefficient in the z-direction

$C_{d x} \quad$ drag force coefficient in the x-direction

$C_{d y} \quad$ drag force coefficient in the $y$-direction

$C_{d z} \quad$ drag force coefficient in the z-direction

E elastic modulus (Pa)

E3 strain gage at the side column

EI flexural rigidity (N.m ${ }^{2}$ )

F1 strain gage at the tower-base

G center of gravity

GM metacentric height (m)

$H_{r} \quad$ regular wave height (m)

$H_{S} \quad$ significant height of the irregular wave condition [m]

$i \quad$ index to represent the degree of freedom

$k \quad$ wave steepness ( $\mathrm{rad})$

$K \quad$ external stiffness $(\mathrm{kN} / \mathrm{m})$ or $(\mathrm{kN} . \mathrm{m} / \mathrm{deg})$

$K B$ distance from the buoyance center to the keel point $(\mathrm{m})$

$K G$ distance from the center of gravity to the keel point (m)

T1 strain gage at the front guy wire

$T 2, T 3 \quad$ strain gage at the side guy wire

$T \quad$ period of the wave (s)

$T_{p} \quad$ period of the peak of the irregular wave condition (s)

$U \quad$ wind speed $(\mathrm{m} / \mathrm{s})$

$v_{x} \quad$ velocity in the $\mathrm{x}$-direction $(\mathrm{m} / \mathrm{s})$

$v_{y} \quad$ velocity in the $y$-direction $(\mathrm{m} / \mathrm{s})$

$x \quad \mathrm{x}$-direction

y $\quad$-direction

\section{References}

1. Borisade, F.; Choisnet, T.; Cheng, P.W. Design study and full scale MBS-CFD simulation of the IDEOL floating offshore wind turbine foundation. J. Phys. Conf. Ser. 2016, 753, 092002. [CrossRef]

2. Beyer, F.; Choisnet, T.; Kretschmer, M.; Cheng, P.W. Coupled MBS-CFD simulation of the IDEOL floating offshore wind turbine foundation compared to wave tank model test data. In Proceedings of the 25th International Ocean and Polar Engineering Conference (ISOPE), Kona, HI, USA, 21-26 June 2015.

3. Pan, J.; Ishihara, T. Numerical prediction of hydrodynamic coefficients for a semi-submersible platform by using large eddy simulation with volume of fluid method and Richardson extrapolation. J. Phys. Conf. Ser. 2019, 1356, 012034. [CrossRef]

4. Ishihara, T.; Zhang, S. Prediction of dynamic response of semi-submersible floating offshore wind turbine using augmented Morison's equation with frequency dependent hydrodynamic coefficients. Renew. Energy 2019, 131, 1186-1207. [CrossRef] 
5. Ohta, M.; Komatsu, M.; Ito, H.; Kumamoto, H. Development of a V-shaped semi-submersible floating structure for 7MW offshore turbine. In Proceedings of the World NAOE Forum 2013 \& International Symposium on Marine and Offshore Renewable Energy, Tokyo, Japan, 28-30 October 2013.

6. Komatsu, M.; Kumamoto, H.; Mori, H.; Ohta, M.; Karikomi, K.; Ishii, H. Comparison between measured value and simulated value of motion and mooring force in Mitsubishi floating offshore wind turbine. In Proceedings of the Grand Renewable Energy 2018 Proceedings, Yokohama, Japan, 18-22 June 2018.

7. Yoshimoto, H.; Natsume, T.; Sugino, J.; Kakuya, H.; Harries, R.; Alexandre, A.; McCowen, D. Validating numerical predictions of floating offshore wind turbine structural frequencies in bladed using measured data from Fukushima Hamakaze. In Proceedings of the EERA Deep Wind 2019, Trondheim, Norway, 16-18 January 2019.

8. Matsuoka, R.; Yoshimoto, H. Verification of precision concerning the design of advanced spar type structure. In Proceedings of the Japan Society of Naval Architects and Ocean Engineers, Kobe, Japan, 25-26 May 2015; Volume 20. 2015S-OS1-1.

9. Yamaguchi, A.; Ishihara, T. Current status of research activity on floating offshore wind turbine in Japan. In Proceedings of the EWEA Offshore 2013, Messe Frankfurt, Germany, 19-21 November 2013.

10. Ishihara, T.; Yamaguchi, A.; Taki, S. The challenge to the world's first floating wind farm. In Proceedings of the Grand Renewable Energy 2014 Proceedings, Tokyo, Japan, 27 July-1 August 2014.

11. Fukuda, T.; Gugai, S.; Hosoya, R.; Sato, S.; Sugiura, S. Experimental study of floating offshore wind farm (FOWF) in Fukushima. In Proceedings of the Grand Renewable Energy 2014 Proceedings, Tokyo, Japan, 27 July-1 August 2014.

12. Van Phuc, P.; Ishihara, T. A numerical study on dynamic response of semi-submersible floating offshore wind turbine system and its verification by experiment. J. Jpn. Soc. Civ. Eng. 2009, 65, 601-617. (In Japanese)

13. Suzuki, H.; Xiong, J.; Carmo, L.H.S.; Vieira, D.P.; Mello, P.C.; Malta, E.B.; Simos, A.N.; Hirabayashi, S.; Gonçalves, R.T. Elastic response of a light-weight floating support structure of FOWT with guywire supported tower. J. Mar. Sci. Technol. 2019, 24, 1015-1028. [CrossRef]

14. Xiong, J.; Carmo, L.H.S.; Vieira, D.P.; Mello, P.C.; Malta, E.B.; Simos, A.N.; Suzuki, H.; Gonçalves, R.T. Experimental and numerical comparison of the wave dynamics and guy wire forces of a very light FOWT considering hydroelastic behavior. In Proceedings of the ASME 2018 1st International Offshore Wind Technical Conference, San Francisco, CA, USA, 4-7 November 2018. IOWTC2018-1057.

15. Carmo, L.H.S.; Vieira, D.P.; Xiong, J.; Malta, E.B.; Simos, A.N.; Mello, P.C.; Suzuki, H.; Gonçalves, R.T. Wave basin testing and numerical analysis of a very light FOWT with guy-wires. In Proceedings of the 27th International Congress on Waterbone Transportation, Shipbuilding and Offshore Constructions, Rio de Janeiro, Brazil, 23-25 October 2018.

16. Shiohara, H.; Gonçalves, R.T.; Houtani, H.; Suzuki, H.; Schnepf, A.; Hirabayashi, S.; Carmo, L.H.S.; Nihei, Y. Numerical and experimental comparison of the wave response of a very light floating offshore wind turbine with guy wires. In Proceedings of the ASME 39th International Conference on Ocean, Offshore and Arctic Engineering, Virtual, Online, 21-30 July 2020. OMAE2020-19163.

17. Jain, A.; Goupee, A.J.; Robertson, A.N.; Kimball, R.W.; Jonkman, J.M.; Swift, A.H.P. FAST code verification of scaling laws for DeepCwind floating wind system. In Proceedings of the 22nd International Offshore and Polar Engineering Conference, Rhodes, Greece, 17-22 June 2012.

18. Suzuki, H.; Shibata, H.; Fujioka, H.; Hirabayashi, S.; Ishii, K.; Kikuchi, H. Development of an analysis code of rotor-floater coupled response of a floating offshore wind turbine. In Proceedings of the ASME 32nd International Conference on Ocean, Offshore and Arctic Engineering, Nantes, France, 9-14 June 2013. OMAE2013-10444.

19. Wheeler, J.D. Method for calculating forces produced by irregular waves. J. Pet. Technol. 1970, $22,359-367$. [CrossRef] 
20. Det Norske Veritas. Recommended Practice DNV-RP-C205 (Environmental Conditions and Environmental Loads); Det Norske Veritas: Høvik, Norway, 2010.

21. Pesce, C.P.; Amaral, G.A.; Franzini, G.R. Mooring system stiffness: A general analytical formulation with an application to floating offshore wind turbines. In Proceedings of the ASME 1st International Offshore Wind Technical Conference, San Francisco, CA, USA, 4-7 November 2018. IOWTC2018-1040.

Publisher's Note: MDPI stays neutral with regard to jurisdictional claims in published maps and institutional affiliations.

(C) 2020 by the authors. Licensee MDPI, Basel, Switzerland. This article is an open access article distributed under the terms and conditions of the Creative Commons Attribution (CC BY) license (http://creativecommons.org/licenses/by/4.0/). 